\title{
Parteiautonomie im Internationalen Immaterialgüterrecht
}

Eine rechtsvergleichende Untersuchung de lege lata und de lege ferenda

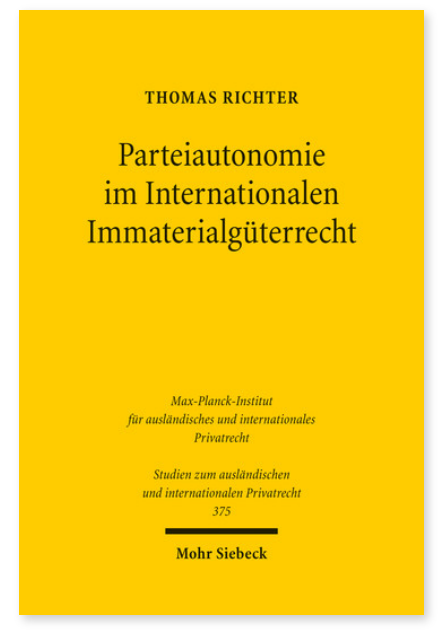

2017. XXXIV, 430 Seiten. StudIPR 375

ISBN 978-3-16-155052-2

DOI 10.1628/978-3-16-155052-2

eBook PDF $94,00 €$

ISBN 978-3-16-154981-6

fadengeheftete Broschur $94,00 €$
Im Zusammenhang mit Immaterialgüterrechten wie Marken, Patenten und dem Urheberrecht genießen das Territorialitätsprinzip und die daraus fließende Anwendung des Schutzlandrechts international Anerkennung. Thomas Richter untersucht die Zulässigkeit und Reichweite der Rechtswahl im Immaterialgüterrecht de lege lata und de lege ferenda. Dabei geht er insbesondere auf die Bedeutung der Rechtswahl für das dingliche Verfügungsgeschäft beziehungsweise die Abgrenzung zwischen Vertragsstatut und dinglichem Statut sowie die Zulässigkeit einer Rechtswahl bei der Verletzung von Immaterialgüterrechten ein. Die Untersuchung erfolgt rechtsvergleichend anhand der bestehenden Kollisionsregeln in der EU, den USA und der Schweiz und bezieht die Lösungsansätze von Modellgesetzen mit ein. Abschließend entwickelt Thomas Richter auf Grundlage der kollisionsrechtlichen Dogmatik neue Regeln unter Berücksichtigung des Interesses der Parteien an Rechtssicherheit und niedrigen Transaktionskosten sowie marktordnungsrechtlicher Erfordernisse im Bereich der Immaterialgüter.

Thomas Richter Geboren 1985; Studium der Rechtswissenschaften an der Bucerius Law School, Hamburg; wissenschaftlicher Mitarbeiter am Lehrstuhl für Bürgerliches Recht, Internationales Privat- und Handelsrecht und Rechtsvergleichung an der Bucerius Law School; Master of Laws an der Boston University School of Law; Referendariat am Hanseatischen Oberlandesgericht; seit 2016 Rechtsanwalt in Hamburg.

Jetzt bestellen:

https://mohrsiebeck.com/buch/parteiautonomie-im-internationalen-immaterialgueterrecht-9783161550522?no_cache=1 order@mohrsiebeck.com

Telefon: $+49(0) 7071-923-17$

Telefax: $+49(0) 7071-51104$ 